\title{
JULIÁN MEZA: LOS CAPRICHOS DEL VIAJERO*
}

Francisco Segovia**

\section{Hay un párrafo que condensa bien} tanto la actitud con que viaja Julián Meza como la forma en que ha decidido contar sus viajes por el Mediterráneo. Es el párrafo que abre las páginas dedicadas a Catania. Dice así:

Según Tucídides, la fundación de Catania está fechada en el año setecientos veintinueve anterior a la regresiva cuenta progresiva del presente. En realidad, data del principio de la edad del cobre, que se remonta al tercer milenio antes del triunfo del monoteísmo romano.

Para empezar (honor a quien honor merece), Tucídides, un historiador clásico... A continuación, una excentricidad: escribir la fecha de la fundación de Catania en letras y no en números, como para quitarle al dato la pomposa objetividad de la que tanto y tan vanamente presumen los historiadores cuando recurren a los números... Luego, una burla a las convenciones cronológicas: "la regresiva cuenta progresiva"; es decir, un comentario sobre la manía de contar en reversa los años que anteceden a Cristo. Pero aquí no es indiferente la forma de enunciar el predicado. En "la progresiva cuenta regresiva" hay algo que no se podría decir de otra manera, pues sólo así se deja ver que, aun

* Sobre Sicilia. La piedra negra, 2008, Jaén, Alcalá Grupo Editorial, y Constantinopla. La isla del mediodía, 2011, México, Ediciones Sin Nombre.

** Escritor. 
siendo retrógrada, la cuenta no puede sino progresar. También las regresiones progresan. Meza no desaprovecha la oportunidad de presentar esto como prueba de que el progreso que tanto ha venerado el Occidente moderno nos conduce a la barbarie...

Y justo ahí, la corrección: Tucídides se equivocaba: Catania, "en realidad, data del principio del la edad del cobre". Esto se presenta como una verdad de veras verdad -al modo que es común entre los historiadores-, pero aquí no viene a cuento para que el autor pueda dárselas de más sabio o acertado que Tucídides, sino para casi lo contrario, para señalar que ningún historiador importante puede ser superado, porque su importancia no depende tanto de la exactitud de sus datos como del valor de su relato; es decir, porque un buen historiador tiene que ser, ante todo, un buen narrador. Por eso está bien decir que Tucídides se equivocaba aquí y allá, pero no está bien, en cambio, olvidarse de él con el pretexto de que sus datos han sido superados. Tucídides está mucho más presente en nuestra tradición que los historiadores que después lo han corregido -a quienes Meza ni siquiera menciona. Porque las correcciones pueden ser importantes, claro, pero no dejan de ser minucias frente a una verdadera obra. Y toda verdadera obra es, a su manera, una obra verdadera, pues su valor no reside tanto en la precisión de sus datos como en la actitud que adopta frente a la historia y en la manera en que esa actitud se refleja en su escritura. Por eso mismo, Meza comenta un error de Heródoto, diciendo que "el historiador era tan objetivo como los fabulistas". No es raro, pues, que el profesor de historia que es Julián Meza no ponga a sus alumnos a leer libros de historia sino novelas...

Y, para terminar, una muestra de bulto de lo que acabo de decir: Meza sitúa la edad de bronce "en el tercer milenio antes del monoteísmo romano". Antes de... ¿Qué?... Esto es un deslizamiento, no un desliz. Como hemos visto, Meza desconfía de la fisura convencional que divide nuestra historia en un antes y un después de Cristo, así que elige evitar el desbarrancadero y, vadeando el vacío, seguir el camino de Pablo - ese "energúmeno", como lo llama en otro sitio. Pablo le dio a Roma ese monoteísmo que habría de asegurar que Roma sobreviviera al mismísimo Imperio romano. Roma por eso es la Ciudad 
Eterna, aunque lo sea sólo porque asimiló la enfermedad que le produjo el cristianismo, al cual a su vez Roma transformó (como se supone que ocurrió con esa rara enfermedad que el cuerpo humano asimiló transformándola en su esqueleto). Esto implica una consideración tácita: sin Pablo, el cristianismo no hubiera sido sino otra de las religiones mistéricas del Medio Oriente, como el mitraísmo o los cultos a Isis -que en Roma fueron poco más que una moda cultural, como lo siguen siendo hoy en París, en Nueva York o en Tepoztlán. Fue pues Pablo “el energúmeno" quien corrompió la historia de Roma con el cristianismo y a la vez corrompió la historia del cristianismo con Roma. Y quizás haya aquí una consideración extra, pues Meza parece suponer que el cristianismo no era "naturalmente" latino, como en cambio podría decirse que era "naturalmente" griego. Lo digo porque trata con verdadera saña a la Iglesia Católica, pero no a la Iglesia Ortodoxa, cosa que sólo puedo explicarme si supongo que Meza supone una continuidad entre la Grecia politeísta y la monoteísta. Y, en efecto, "los bizantinos -dice Meza- son los griegos de la Edad Media”.

He escrito ya una página entera, y no he comentado más que tres líneas de Julián Meza. Está claro, pues, que hallo mucha miga en ellas, y que en ellas veo una imagen de su autor en cuanto viajero y en cuanto lector (un lector es siempre un viajero; y un viajero es siempre, a su modo, un lector -pero ojo: un viajero, no un turista). En esa imagen se adivina también al escritor y al profesor de historia que es Julián Meza. Pero tres líneas no son suficientes, y la imagen que estoy formando es aún borrosa. Para enfocarla debo hallar el punto del que todo arranca, la invitación al viaje, como diría Baudelaire. La encuentro en tres sitios principales. El primero es, sin duda, la literatura (entendida ésta como un género que comprende a la historia). Así, por ejemplo, en la introducción al libro sobre Sicilia, dice Meza que las páginas que escribió sobre su viaje habrían de conformar "un libro de retales donde estarían presentes los viajes, el ensayo, la historia y la ficción”. Sin embargo,

No sabía cómo empezar [...] Buscando un libro de Ítalo Calvino, La especulación inmobiliaria, me topé con otro, que había olvidado: Las ciudades invisibles. Su lectura me sacó del apuro, o así lo creo. Espero 
no haber saqueado [...] sus ideas; sí, en cambio, haberlas ramificado, distorsionado, adaptado a mis caprichos de viajero.

La segunda invitación es más bien personal y hasta psicológica. En ese mismo libro ha escrito Meza estas palabras: "Nadie elige el sitio donde nace. Puede hallar, sin embargo, el lugar o los lugares de donde realmente es". Nótese que aquí Meza no cede a la tentación de las frases simétricas. Estilísticamente, uno esperaría que a la oración que dice que "uno no elige el sitio donde nace" le siguiera otra que dijera "pero puede en cambio elegir el sitio de donde es". Pero él no dice eso. No dice que él elige el sitio de donde es, como dirían sin duda los modernos; dice, en cambio, que lo halla, como seguramente habrían dicho los antiguos. Esos sitios se le imponen, pues, como cifra de un destino. Y por ver ese destino se echa a andar. Su viaje es un viaje en el sentido literal del término, pero también en el metafórico. Como Edipo, Meza entiende finalmente que sólo puede hallarse el destino en la historia, en el relato de la historia; es decir, entiende que enfrentarse al destino no es distinto de re-construirlo, de re-pasarlo, de re-cuperarlo. Por eso, más adelante agrega que ha ido a Sicilia "para recuperar el mundo de la Magna Grecia, a Constantinopla para recuperar Bizancio, a Cerdeña 216 para recuperar Catalunya [...] a Catalunya para recuperarme a mí mismo". Meza nació en Orizaba, Veracruz, es cierto, pero es de Barcelona, de París, de Palermo, de Lisboa, de Constantinopla, Malta, Atenas. Todo lo que lo llama o le gusta es una isla del Mediterráneo. Sí, incluso Lisboa está en el Mediterráneo para él; y sí, también Constantinopla, Barcelona y París son islas para él. Meza reduce a su gusto todo lo que es de su gusto. "No estoy sometido a la dictadura de la geografía", dice con suficiencia, y como para advertirnos de que, si uno quiere errar con él por esos lares, debe someterse a sus "caprichos de viajero". No digo que sea fácil, ni que uno no vaya a hacer algunas rabietas durante el viaje, pues no está en la naturaleza de Meza expresar los argumentos de sus juicios. (Es un obvio error, por ejemplo, decir que los árabes introdujeron el chocolate en Europa -y estoy seguro de que Meza sabrá reconocerlo-, pero seguramente será más difícil convencerlo de que se equivoca cuando dice que los egipcios "no fueron grandes conquistadores", cuando de hecho 
dominaron las tierras donde hoy se asientan no sólo el propio Egipto, sino también Libia, Sudán, Eritrea, Israel, Líbano, Siria y buena parte de Turquía, por sólo hablar de tierra firme). Pero, ¿quién que viaja en compañía de otro no tiene desacuerdos con él? En todo caso, el placer del viaje paga con creces esos breves descuidos, y los desacuerdos, y aun todos los disgustos.

Esto me lleva a mencionar algo muy importante, situado a medio camino entre la segunda invitación y la tercera: Julián Meza nunca viaja solo. O, si alguna vez lo hace, entonces no considera el viaje digno de ser narrado. Con él va siempre Philareti, que es no sólo su compañera de viajes, sino el símbolo del viaje mismo. Porque esta mujer (a medias real y a veces imaginaria, como todas) no representa propiamente la invitación al viaje, pero sí su sentido último, que es inasible. Por eso vive en el misterio, a medias en la realidad y a medias en el deseo. Y acaso eso justifique que Meza vacile al escribir su nombre - a veces con pe hache, a veces con efe (Philareti, Filareti). En cualquier caso, el viaje que hace con ella empieza en la bruma; el relato, al salir de ella. Meza comienza su libro sobre Constantinopla con una especie de frontispicio, un breve diálogo titulado justamente "Al salir de la bruma". Aunque no se indica quiénes hablan en él, uno adivina que son Julián Meza y Philareti. Yo me atrevo a suponer, además, que -en su papel de hada madrina y al mismo tiempo de Virgilio- es ella quien habla primero:

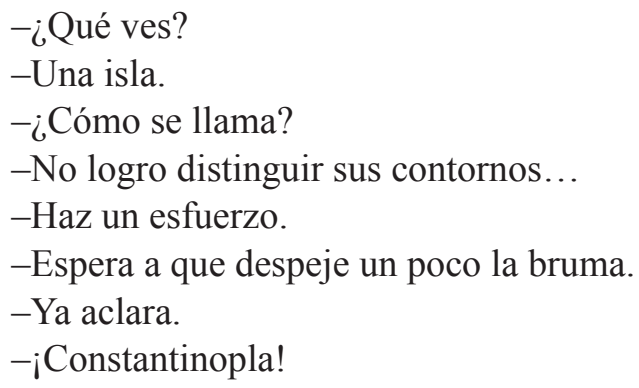

Este diálogo me recuerda unos versos de Seferis. Como Meza menciona a Seferis varias veces en sus libros, no sería extraño que tuviera en mente el poema XXIII de Mythistórima cuando escribió su diálogo. Cito 
a continuación el poema, en la versión que hemos hecho al alimón Selma Ancira y yo. Supongo que no sobrará añadir que Julián Meza dedicó su libro sobre Sicilia a esta misma Selma Ancira, cosa que refuerza mi conjetura. El poema de Seferis dice así:

\author{
Un poco más \\ y veremos florear a los almendros \\ brillar al sol los mármoles \\ al mar romperse en olas \\ un poco más, \\ alcémonos aún un poco más.
}

Así, desde la borda de un barco, se van aclarando las cosas. O sea, poco a poco, muy poco a poco. Después de exclamar " $¡$ Constantinopla!", y al momento de arrancar el relato del viaje propiamente dicho, a Meza le quedan todavía algunos jirones de bruma en los ojos. Escribe entonces otras dos líneas sustanciosas:

En compañía de Philareti, llego por segunda vez a Constantinopla al despuntar la madrugada del 27 de marzo de 2005.

Llego, no llegamos. Por lo tanto, el viaje es el del narrador y Philateri es imaginaria... Pero llegó en compañía. Philareti, aun si imaginaria, lo acompaña. Su nombre es simbólico, es un apodo cariñoso, quizás simplemente un pseudónimo, algo que está ahí en vez de un nombre verdadero... (Pero acaso los nombres verdaderos no sean los que tenemos sin haberlos elegido sino los que hallamos, como esos lugares de donde finalmente somos)... Y entonces cae la piedra: llego... el 27 de marzo de 2005. Eso es un hecho, y está puesto ahí para meternos de lleno en la historia. Sí, pero, ¿en cuál historia? Ni la lengua española ni, mucho menos, Julián Meza dividen la historia en history y story, en realidad y ficción. Para ellos, las dos cosas son la misma historia. Philareti es imaginaria y es real, como la historia misma, como el viaje, como el viajero y su sombra. 
La tercera invitación no viene signada por un nombre simbólico ni por un apodo cariñoso, pues es la invitación de un amigo -y uno no sólo no tiene por qué ahorrarse en público el nombre de un amigo, sino que aun no está bien que lo haga. Ése nombre es el de Álvaro Mutis. A él está dedicado el libro sobre Constantinopla: "A Álvaro Mutis, naturalmente". La explicación de ese "naturalmente" no se encuentra en el libro sobre Constantinopla, sino el libro sobre Sicilia. Hemos visto ya que Meza relata su segundo viaje a Constantinopla, no el primero. ¿Por qué, si Philareti también estuvo en él? La única explicación que puedo dar a esto es que en el primero faltaba Mutis. Philareti representa la Grecia clásica-que está mejor conservada en Sicilia que en la propia Grecia, como deja bien claro Julián Meza-; Mutis, en cambio, representa Bizancio; es decir, la Grecia medieval. Y nuestra Bizancio, ya se sabe, es casi toda ella invención de Mutis. Es famosa la Presentación del "Material de lectura" dedicado a Mutis donde él mismo declara, sin muchos ambages: "Nunca he participado en política, no he votado jamás y el último hecho político que me preocupa de veras es la caída de Bizancio en manos de los infieles en 1453. Soy gibelino, monárquico y legitimista". Gibelino; es decir, partidario de los emperadores alemanes en su enfrentamiento con los Papas. Los infieles; por tanto, no es un enemigo de la religión cristiana quien habla, sino un adversario del catolicismo apostólico romano. Bizancio; ah los griegos medievales... Como se ve, ésta es la carta de navegación que sigue Meza en su recorrido por Constantinopla. Él mismo lo confiesa así, aunque en el libro dedicado a Sicilia: "Volví a ese país motivado por el impulso que me dio Álvaro Mutis: el descubrimiento de Bizancio y, en particular, de Constantinopla". Pero lo reitera, un poco más extensamente, en el libro sobre Constantinopla: "Si nunca hubiera conocido a Álvaro Mutis es casi seguro que jamás habría vuelto a Turquía, que hoy es para mí, como siempre ha sido para él, Bizancio, ni a su capital, que no es Istambul (ni menos aún Estambul) sino Constantinopla. La primera vez que desembarqué en la capital de esa geografía creí que estaba en Istambul. Esta vez fui decididamente a Constantinopla”. Testimonio de esta invitación a Bizancio es un libro curioso, firmado por Mutis, pero más bien obra de Meza: La muerte del estratega. Y tres 
FRANCISCO SEGOVIA

conversaciones con Julián Meza, publicado por el Fondo de Cultura Económica, la UNAM y El Equilibrista en 2007. Se entiende que las conversaciones tienen como tema central "La muerte del estratega", ese relato extraordinario en donde Mutis ha plasmado su visión de Bizancio. Pero lo que importa aquí es el cambio cualitativo que esa obra y su autor produjeron en Julián Meza. Por gracia de Álvaro Mutis, su segundo viaje ya no es a Istambul, sino a Constantinopla.

Quizá Julián tolere que yo le diga ahora que en su primer viaje no fue sino eso que él mismo tanto execra y vitupera; es decir, un vil turista. Fue a Constantinopla y no vio nada de lo que de veras le tocaba, porque sólo vio Istambul. Y fue preciso que volviera a México para que aquí un colombiano que se halló en México (un mexicano nacido en Colombia) le mostrara en detalle todo lo que había perdido allá (todo de lo que allá se perdió). Tendría pues que volver a Turquía, si de verdad quería hallar otro de los sitios de donde es; tendría que ir allá por segunda vez, si quería hallarse. Es una de esas verdades que sólo pueden decirse jugando con la lengua, pues solamente así puede aludirse al misterio que las envuelve. La expresaré así: uno siempre se va de donde no se halla. Coloquialmente, esta frase significa que uno se va de los lugares donde no está a gusto (pero ¿de dónde ha sacado nuestra lengua que uno sólo se halla donde le gusta estar?). Fuera de esta acepción coloquial, la frase no puede significar sino algo ilógico, pues ¿cómo puede uno irse de donde no se encuentra? Hay que tener cuidado, sin embargo. Una falta de lógica no siempre es, además, una falta de sentido, y por eso he dicho que la frase significa algo aun cuando ese algo no se apegue del todo a la lógica. Ese algo, creo yo, mienta la misma paradoja del tiempo, que también Heráclito expresó echando mano de un juego de palabras: uno se baña y no se baña dos veces en el mismo río. La lógica dice que, en el primer caso, el río designa el cauce por donde fluye el río; en el segundo, en cambio, designa la corriente que fluye por ese cauce. Pero si el sentido de la frase se agotara en esas dos afirmaciones lógicas, entonces no se habrían escrito tantas páginas sobre ella (y Meza no podría agregar que en el río de Heráclito se han bañado también Borges, Apollinaire y quién sabe cuántos más). No, lo miste- 
rioso de la frase de Heráclito es que exprese ambas cosas en un solo enunciado, como el español expresa en una sola palabra (historia) algo que al inglés le toma dos (history y story). Así como destramar lógicamente las acepciones de historia saca la palabra del uso para meterla al diccionario, así también el análisis lógico de la frase de Heráclito mata su intuición y su misterio. Julián Meza, desde luego, se abstiene de semejante barbaridad. Y no seré yo quien se convierta en el gran desconstantinopolizador desconstantinopolizando a Julián el Apóstata... Sin embargo, aún hay algo que debo añadir a este respecto.

Por más que Meza haya encontrado los lugares de donde es (y aun nos falta leer los libros que ya ha anunciado sobre Cerdeña y Grecia); por más que haya encontrado los sitios de donde es - digo--, no puede hurtarse a la otra cara del destino: ser también de donde nació. Ese sitio, que él no halló, lo haya en cambio a él por todos lados. Y Meza no le vuelve la espalda. Al describir Messina, por ejemplo, su referente es México. Dice: "Entrar en la ciudad es como incursionar en la Colonia de los Doctores en la capital de México. Sólo le faltan las taquerías". Sobre el mar de Messina "pende una luna llena de un tamaño y un color sólo posibles ahí, en Istambul (sí: Istambul) o Zacatecas”. Pero hay más. Al visitar Morgantina, Meza siente que Philareti y él ya han estado ahí. "Tal vez - dice- estuvimos ahí antes de haber llegado por primera vez". Otra vez la paradoja temporal, como refrendo de aquello que antes dije sobre el re-lato y la re-cuperación, pero también de esa frase de la contraportada (seguramente obra de José María Espinasa) donde se afirma que los buenos viajeros siempre llegan a donde llegan por segunda vez. Son dos maneras de decir lo mismo, una vez aludiendo al relato y la otra al mito -que es un relato. Pero acaso valga la pena agregar que quien es consciente de entrar al río por segunda vez sabe por fuerza que está condenado a hacerlo eternamente; es decir, sabe que su entrada sólo puede expresarse imaginariamente. Por eso Meza termina su estampa morgantina diciendo que "tal vez nunca estuvimos en ese sitio, pero fuimos capaces de imaginarlo sin mayor esfuerzo porque era nuestro sólo por estar ahí, intacto”. ¿Se trata entonces de un mero sueño? Aun si así fuera, ¿qué puede importarle eso a un autor 
que dice que "en el contacto con lo inmutable el tiempo vuelve a ser sagrado"? Tampoco a mí me importa si la experiencia de Morgantina es un sueño o no, pero no puedo dejar de señalar que, inmediatamente después de estar en contacto con lo intacto (cosa de por sí paradójica), Meza inicia una nueva estampa, titulada justamente "La ciudad y el sueño". Como es breve, la cito entera:

La ciudad no es lo que pienso de ella, sino lo que me hace decir, allá y aquí, de lejos y de cerca. Tal vez mis palabras la recuperen como quiere que lo haga, aun cuando no la pueda describir, por respeto, o por temor, porque siempre está lejos de mí, porque me resulta inasible, porque se me escurre entre los dedos como la arena o el agua. La amo y la detesto; soy su víctima y su verdugo, en particular cuando sobrevivo en uno de sus supuestos paraísos tropicales: México.

La ciudad me produce cosquillas, pero no me río.

Mi mirada y mi deseo despiertan el pasado de su letargo milenario.

Excavo en el suelo con los ojos y, con furia, arrojo la tierra al aire en el pensamiento.

La ciudad que amo y detesto no es, obviamente, Morgantina, pero de algún modo me invita a pensar en aquella que es, en toda la magnitud de presente, y no quisiera que fuera, mía: México.

Una frase me llama la atención: "La ciudad me produce cosquillas, pero no me río". Y es que todos, supongo, nos hemos hecho esta pregunta: ¿por qué me río cuando otro me hace cosquillas, pero no cuando me las hago yo? Nadie se ríe de las cosquillas que se hace a sí mismo. Eso es tal vez lo que le pasa a Julián Meza: la ciudad que le hace cosquillas es él mismo. Por eso no se ríe. Julián el Apóstata podrá reírse de todos los destinos, pero no del suyo. No puede reírse de Philareti, ni de Álvaro Mutis, ni de Constantinopla, ni de Barcelona, ni de Orizaba. Puede burlarse de todo, hasta del Papa, pero no de los sitios en donde se halla, de las ciudades de donde halla que es. De todo, menos del sueño en que son de veras reales la amistad, el amor, los libros y los viajes.

Muchas gracias. 